\title{
8. Gesundheitspflege-Kongress Hamburg
}

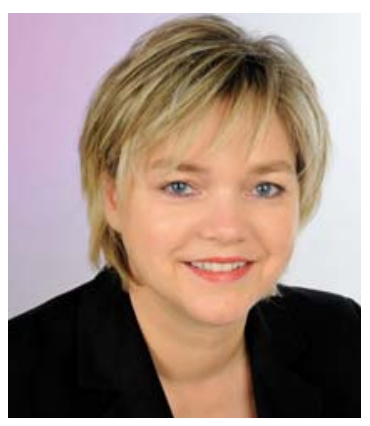

Andrea Tauchert, Berlin

Leitung Kongressbüro andrea.tauchert@springer.com heitswissenschaften/Public Health, unter Einbeziehung der stationären und ambulanten Pflege sowie der Altenhilfe und Altenpflege, präsentiert und diskutiert werden. Wir laden Sie ein, die Beiträge kritisch zu lesen - sei es zur Vorbereitung auf den Kongress oder um im Anschluss Gehörtes noch einmal zu vertiefen. Aber natürlich freuen wir uns auch darauf, Sie am 19. und 20. November auf dem Kongress in Hamburg begrüßen zu dürfen.

Ihre

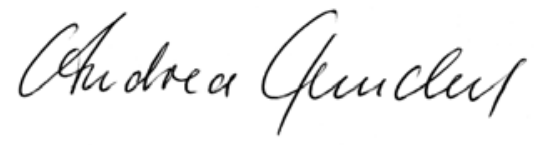

Ihr

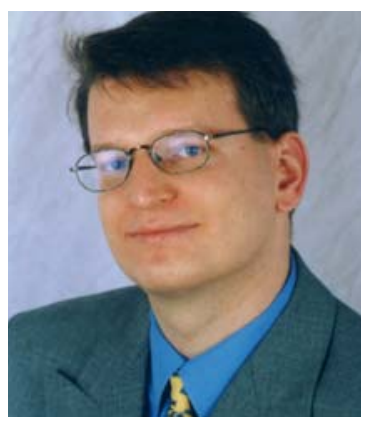

Prof. Dr. med. habil. Jörg Klewer, Zwickau

Schriftleitung heilberufescience@springer.com

HeilberufeSCIENCE 2010; 1 (5): 3 DOI 10.1007/s16024-010-0501-6
Die Sonderausgabe gliedert sich in drei Teile: Im ersten finden Sie die alphabetisch gegliederten Abstracts ausgewählter Kongressbeiträge. Diese spiegeln die Schwerpunkte des 8. Gesundheitspflege-Kongresses wider, wie die Umsetzung des neuen Pflegebedürftigkeitsbegriffs, Nachwuchsgewinnung im Pflegebereich, Akademisierung in der Pflege oder den demografischen Wandel im Gesundheitswesen. Der zweite und dritte Teil umfassen jeweils die Abstracts der Postersession sowie die Abstracts des damit verbundenen wissenschaftlichen HeilberufeSCIENCE-Symposi-

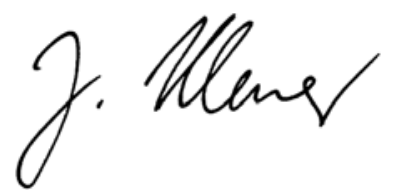

